\title{
IMPACTOS AMBIENTAIS DO ALQUIL BENZENO SULFONADO LINEAR
}

\author{
R. F. CAVALCANTE, G. M. MARINHO e B. C. A. BARBOSA \\ Instituto Federal do Ceará - IFCE \\ reinaldo77_fontes@yahoo.com.br
}

Artigo submetido em janeiro/2013 e aceito em fevereiro/2014

DOI: $10.15628 /$ holos.2014.1247

\section{RESUMO}

O uso de surfactantes tem crescido em todo o planeta níveis exponenciais e o alquil benzeno sulfonado linear (LAS) é o surfactante aniônico mais utilizado em todo o globo com uma produção anual de 2,8 milhões de toneladas. Devido a isso cresce a preocupação com os efeitos adversos que a disposição inadequada desta substância acarreta para o meio terrestre e o meio aquático. A ação nociva, do surfactante LAS, a vida da biota destes ambientes se dão principalmente devido a ruptura da membrana celular através da interação com os componentes lipídicos, e a reação com enzimas fundamentais para o funcionamento das células, efeitos estes intensificados pela sua concentração. Nos ambientes aquáticos o LAS pode acarretar alterações nas taxas de oxigenação natural, deficiência na reprodução de peixes e invertebrados, eutrofização e situações de escassez qualitativa de recursos hídricos. foi observado que os efluentes de origem doméstica são os principais contribuintes do Alquil benzeno sulfonado Linear(LAS) e que a degradação biológica do LAS pode ocorrer a níveis de eficiência que chegam a $80 \%$ e ainda que pode ser potencializada com a ação combinada com processos físico químicos. Concentrações abaixo de $0,29 \mathrm{mg} / \mathrm{L}$ reduzem seus efeitos nocivos sendo o tratamento deste surfactantes aniônico um fator estratégico para o incremento da oferta hídrica e da preservação dos recursos naturais da região

PALAVRAS-CHAVE: Impactos Ambientais, Aquil Benzeno Sulfonado Linear..

\section{ENVIRONMENTAL IMPACTS OF LINEAR ALKYL BENZENE SULFONATE}

\begin{abstract}
The use of surfactants has grown around the planet exponential levels and linear alkyl benzene sulfonate (LAS) is the most used anionic surfactant across the globe with annual production of 2.8 million tons. Because of this growing concern about the adverse effects that the improper disposal of this substance leads to the terrestrial and aquatic environment. The harmful action, the surfactant LAS, the life of the biota of these environments occur mainly due to disruption of the cell membrane through interaction with lipid components, and reaction with enzymes essential to the functioning of cells, these effects enhanced by its concentration. In aquatic environments the LAS may cause alterations in
\end{abstract}

rates of natural oxygenation deficiency on reproduction of fish and invertebrates, eutrophication and qualitative shortages of water resources. was observed that the effluent from domestic sources are major contributors of Linear Alkyl benzene sulfonate (LAS) and the biological degradation of LAS can occur at efficiency levels that reach $80 \%$ and even that can be increased by the combined action with processes physical chemical. Concentrations below $0.29 \mathrm{mg} / \mathrm{L}$ reduce its harmful effects and the treatment of this anionic surfactants a strategic factor for increasing the water supply and the conservation of natural resources in the region.

KEYWORDS: Environmental Impacts, Aquil Benzene Sulfonate Linear.. 


\section{INTRODUÇÃO}

É fato que o planeta passa por uma profunda crise ambiental sem precedentes na história. O início do século XXI é marcado por grandes preocupações e profundas reflexões sobre nosso estilo de vida extremamente agressor e parasitário dos recursos naturais existentes no globo. Fatores como disponibilidade de água, alimento, energia, minérios e madeira têm conduzido a humanidade a passos largos para um colapso ambiental como nunca visto e a uma situação de escassez extrema de recursos indispensáveis à manutenção da vida na Terra. Desta maneira a diminuição da pressão sobre os fatores que comprometem a qualidade ambiental de uma determinada localidade se torna um ponto estratégico para o alcance do desenvolvimento de uma região. (Braga et al. 2002)

Nas últimas décadas presenciamos um crescimento de forma exponencial na produção mundial de surfactantes, substâncias estas utilizadas nas formulações de sabões, detergentes, tecidos, tintas, polímeros, pesticidas, produtos farmacêuticos, mineração, recuperação de vazamentos de óleo e as indústrias de celulose e papel (Di Corcia, 1998). Este crescimento está associado às novas necessidades da sociedade moderna e os avanços tecnológicos, agregando a composições destas moléculas mecanismos mais complexos visando atingir maiores eficiências na retirada de materiais específicos, diminuição do tempo de remoção e preservação de objetos e estruturas. Segundo Garcia et al.(2005), características físico químicas e moleculares favoráveis e seu custo relativamente baixo fizeram do LAS o surfactante aniônico mais utilizado em todo o globo, representando cerca de $40 \%$ de todo o surfactante comercializado no planeta. A produção mundial do surfactantes foi de 2,8 milhões de toneladas anuais ( GARCIA et al. 2005).

O LAS comercial é constituído de uma mistura de vários homólogos e isômeros de posição de cadeias alquiladas lineares, com a quantidade de carbono variando principalmente entre 10 e 14 átomos, possui uma parte hidrofílica onde se observa um anel aromático sulfonado na posição - para ligado a cadeia linear alquil. Esta ligação pode aparecer em qualquer posição na cadeia linear com exceção dos carbonos localizados nas extremidades da cadeia alquílica como observado na figura 1 (MATHEUS; DEHENAU, 1987).

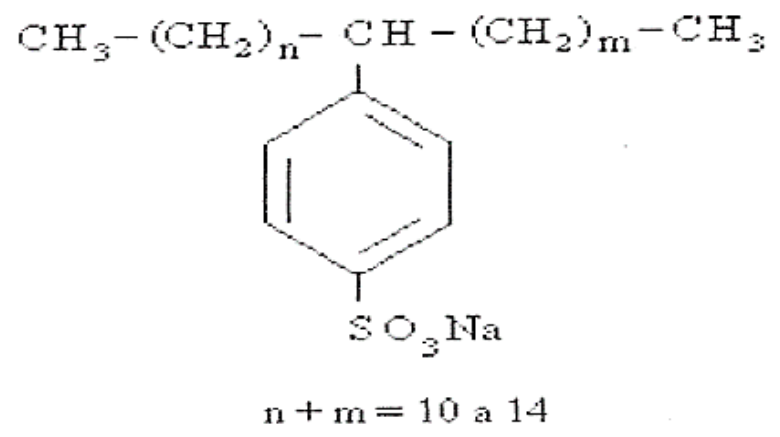

Figura 01- Fórmula estrutural do Alquil Benzeno Sulfonado Linear Fonte: (Oliveira et al. 2010).

O estudo de tecnologias relacionadas com a bioremediação do LAS, assim como os impactos ambientais causados pela disposição inadequada das significativas descargas deste 
produto em todo o planeta tem se tornado um ponto relevante nos estudos que buscam 0 crescimento sustentável das cidades (GARCIA et al. 2000).

O objetivo deste trabalho é fazer uma revisão na literatura sobre os principais impactos ambientais no solo e nos ambientes aquáticos causados pelo surfactante aniônico: Alquil benzeno sulfonado linear, assim como suas principias formas de remoção.

\section{IMPACTOS AMBIENTAIS OCASIONADOS PELO LANÇAMENTO DO LAS NO SOLO}

O LAS têm sua toxicidade relacionada com o comprimento da cadeia alquílica apolar e com o tipo de grupamento polar ligado a cadeia. Cadeias alquilicas mais longas podem causar efeitos mais severos.

Esta substância pode chegar ao solo através da disposição inadequada do esgoto e do lodo diretamente no solo ou através das áreas de vazantes dos corpos hídricos receptores. Volkering (1998), afirmou que condições de pH mais baixo, favorecem o aumento das taxas de toxicidade para surfactantes aniônicos, como o LAS.

Uma vez no ambiente o LAS pode causar modificações severas na ecologia e nas relações dos microrganismos responsáveis pela sanidade do solo. De acordo com Paul e Clark (1996), umas parcelas importantes destes microrganismos habitam uma estreita faixa na superfície do solo, em zonas com poros que variam de 2 a $6 \mathrm{~mm}$ de diâmetro, onde estes organismos podem encontrar nutrientes e água para seu desenvolvimento e ainda proteção contra predadores. As presenças destes organismos no solo conferem uma gama de característica relevante ao solo como fertilidade, capacidade de armazenamento de matéria orgânica, de decomposição de substâncias e etc. Estes grupamentos de microrganismos são os prioritariamente mais afetados com as alterações e toxicidade conferida pelo Alquil benzeno sulfonado Linear.

De acordo com Helenuis e Simons (1975), os surfactantes atuam de maneira tóxica em microrganismos através de dois mecanismos principais:

a) A ruptura da membrana celular através da interação com os componentes lipídicos.

b) Reação com enzimas fundamentais para o funcionamento das células.

O LAS ainda pode ter sua toxicidade aumentada com o posicionamento do grupo aromático da molécula, segundo Oliveira (2010), a proximidade do grupo aromático da extremidade da cadeia alquilica tem potencializado as propriedades hidrofóbicas e hidrofílicas acentuando suas respectivas interações.

Segundo Marchesi et al. (1991), a ação dos surfactantes no solo produzem modificações nas formas de agregação e associação dos microrganismos no solo com o desprendimento de bactérias sésseis, aderidas nas partículas de solo. A aderência dos microrganismos no solo traz alterações nas características do meio levando a fatores como: o desequilíbrio ecológico, deficiências na difusão e absorção de substâncias importantes como os nutrientes e uma fragilidade no que tange a capacidade de recuperação natural (JACKSON et al. 1994). Esta alteração promovida pelo surfactante pode ser explicado por meio três mecanismos básicos:

- Através da alteração da carga superficial das bactérias

- Pela prevenção da floculação 
- Pela dissolução dos polímeros extracelulares responsáveis pela formação do biofilme.

Venhuis e Mervar (2004), afirmaram que concentrações de 40 a $60 \mathrm{mg}$ LAS/L podem trazer prejuízos à reprodução e crescimento de invertebrados, como crustáceos e anelídeos, e apresentar graves problemas á biota de ambientes marginais lênticos e lóticos. Associado a isso, foi observada pelos pesquisadores a diminuição da atividade biológica em solos da Alemanha com sua intensidade diminuída com a disposição de lodo seco oriundo de estações de tratamento de esgoto (ETEs), aplicados diretamente no solo. A concentração média de LAS no lodo seco destas estações variavam de $530 \mathrm{mg}$ LAS/Kg a $16.000 \mathrm{mg}$ LAS $/ \mathrm{kg}$ o que pode representar um fator limitante para áreas que utilizam o reúso agrícola como forma de aumento da oferta hídrica na região e uma maneira adequada de preservação dos corpos hídricos receptores das localidades.

Mieure et al. (1990) observaram que plantas expostas ao LAS apresentaram uma alta taxa de destruição das membranas das células radiculares, alterações na permeabilidade e nos processos fotossintéticos e fisiológicos. Ainda segundo Mieure et al. (1990), em cultivos utilizando plantas hidropônicas e outros meios não foram relatados problemas com concentrações de LAS que variavam de 5 a $10 \mathrm{mg} / \mathrm{kg}$. Porém, quando os autores estudaram as concentrações de LAS que variavam de 10 a $40 \mathrm{mg} / \mathrm{kg}$ se percebeu efeitos nocivos descritos acima relacionado com a toxicidade do composto como destruição das membranas radicalares e alterações em processos fisiológicos e fotosintéticos.

\section{IMPACTOS AMBIENTAIS OCASIONADOS PELO LANÇAMENTO DO LAS NOS AMBIENTES AQUÁTICOS}

Segundo Painter e Zabel (1989), As principais fontes de lançamento de surfactantes, nos ambientes aquáticos, se dão sob a forma da disposição inadequada dos efluentes doméstico dos centros urbanos. Os esgotos de origem doméstica têm uma concentração média de LAS que variam de 3 a $21 \mathrm{mg} / \mathrm{L}$. Estas variações dependem de uma série de fatores como cobertura de saneamento, tipo de tecnologia aplicada ao tratamento de efluentes, hábitos da população, características físicas, químicas e microbiológicas dos corpos hídricos receptores entre outras.

As inibições nos processos de autodepuração dos corpos hídricos ocorrem como conseqüência da formação de espumas, disseminação de impurezas, e principalmente, com deficiências nas taxas de oxigenação natural dos corpos aquáticos. Ainda segundo Painter e Zabel (1989), 80\% do LAS pode ser decomposto por degradação microbiana aeróbica. Desta forma, problemas na aeração natural dos ambientes aquáticos contribuem para o aumento da concentração do alquil benzeno sulfonado linear e a diminuição das taxas de reprodução de microrganismos aeróbicos. Esta situação é agravada com a entrada de nutrientes, fomentadas por substâncias presentes na composição do esgoto doméstico, proporcionando um aumento da oferta de nutrientes o que leva, de forma acelerada, a uma condição de eutrofização nestes ambientes aquáticos. Esta condição contribui para condições de anaerobiose e perdas significativas de biodiversidade e qualidade das águas da região, levando a uma situação de escassez qualitativa de recursos hídricos (VERGE e MORENO, 2000).

Os mesmos autores afirmam que a toxicidade aguda do LAS em ambientes aquáticos varia 1,7mg/L a $27 \mathrm{mg} / \mathrm{L}$, sendo a Daphnia magna mais sensível a estas concentrações de LAS, Buhl e 
Hamilton (2000), verificaram sintomas típicos de toxicidade em trutas juvenis da espécie Oncorhynchusmykiss, truta arco íris com uma concentração de $5 \mathrm{mg} / \mathrm{L}$ de LAS.

De acordo com Venhuis e Mehrvar (2004), concentrações que variam de 0,02 mg/L a 1,0 $\mathrm{mg} / \mathrm{L}$ de LAS em ambiente aquático já representam prejuízos ao funcionamento das guelras dos peixes ocasionando excesso de secreção neste órgão. Segundo os mesmos autores foi observado também danos aos padrões de natação em larva de mexilhão azul.

Fairchid et al. (1993), observou que o LAS tem um impacto negativo sobre a sobrevivência de nanoflagelados heterotróficos e ciliados em concentrações de LAS acima de 0,36 mg/L. Belanger et al. (2002), estimaram várias concentrações de LAS não observado efeito na população aquática em concentrações inferiores a $0,29 \mathrm{mg} / \mathrm{L}$ de LAS que foi baseado em uma ampla gama de organismos. Em todos os estudos se observou como chave para proteger o ambiente do impacto negativo do alquil benzeno sulfonado linear o tratamento biológico nas estações de tratamento de esgoto (ETEs).

\section{MECANISMOS DE TRATAMENTO PARA A REMOÇÃO DO LAS}

Um dos grandes desafios ambientais do Brasil para o século XXI continua a ser o tratamento dos efluentes domésticos e industriais através da universalização do saneamento ambiental. A carência nos sistemas de saneamento tem contribuído de forma decisiva para a deterioração dos corpos hídricos superficiais e subterrâneos do país, limitações de seus múltiplos usos e reinserção de uma gama de compostos presentes nos efluentes nos processos produtivos (TELLES e COSTA, 2007).

A remoção de LAS se dá basicamente através de processos biológicos com a oxidação microbiana e através de processos químicos: Adsorção e Processos oxidativos avançados (POAs). Os processos biológicos se mostram mais econômicos quando comparado a outros métodos de tratamento, estes são as principais formas de remoção do surfactante com valores em torno de $80 \%$ de eficiência, e que podem ser potencializados pela ação combinada com os processos físicos e químicos como por exemplo a sedimentação e a adsorção. (DUARTE, et al. 2008).

A remoção do composto das estações de tratamento de esgoto possibilita a diminuição dos impactos ambientais negativos dos surfactantes em nos corpos hídricos receptores das Estações de Tratamento de Esgoto (ETEs), águas subterrâneas e solos da região. (PAINTER e ZABEL,1989).

Existem diversos fatores que podem influenciar na biodegradação do LAS, como estrutura molecular do surfactante, condições químicas do meio, o tipo de microrganismo entre outras (YING.G-G,2006). A decomposição incompleta do LAS gera compostos como carboxilados e sulfenilicos, estes podem ser encontradas em corpos hídricos receptores das ETEs, merecem atenção e monitoramento das autoridades ambientais regionais, o que tem sido negligenciado em muitas regiões. Concentrações superiores a $100 \mathrm{ppb}$ de LAS foram encontrados em corpos aquáticos próximos aos pontos de descargas de ETEs na Espanha (ALVEZ-MUNÕS et al. 2007).

De acordo com Schörbel (1989) a rota de degradação do LAS, em condições aeróbias, ocorre em etapas chamadas de biodegradação primária e final. Na biodegradação primária se observa a modificação da molécula ocorrendo mudanças nas características do composto. Como produto final da biodegradação se observa a formação de gás carbônico $\left(\mathrm{CO}_{2}\right)$, água $\left(\mathrm{H}_{2} \mathrm{O}\right)$, sais minerais e biomassa (SCOTT E JONES,2000). 
Os processos aeróbicos de degradação do LAS ocorrem através da ação de enzimas específicas, como alcano monooxigenase e deidrogenases, atuando basicamente em três estágios escritos por SCHÖRBEL (1989):

- Na primeira fase ocorre o ataque ao grupamento alquil da molécula do surfactante com a conversão oxidativa de um ou dois grupos metila terminais, a chamada $\omega$ oxidação, ocorrendo à conversão da cadeia alquílica a um grupo carboxila. Em seguida a $\beta$-oxidação do grupo carboxila ocorre com a transformação do grupamento e a conversão do mesmo a dióxido de carbono e água. Devido aos muitos homólogos do LAS o tamanho da cadeia carbônica influenciará no processo da $\beta$-oxidação, nos casos de cadeias muito longas a cadeia poderá ser degradada com a perda de um átomo de carbono por vez ( $\alpha$ oxidação);

- No segundo momento ocorre à quebra da ligação C-S com liberação do grupo sulfônico, podendo ocorrer através de dessulfonação oxidativa com a produção de sulfatos, catálise monoxigenase sob condições ácidas e dessulfonação redutiva com a produção de sulfitos e sulfetos;

- No terceiro estágio ocorre o ataque ao anel aromático e a quebra das ligações C-C resultando na abertura do composto aromático e culminando na mineralização do mesmo através dos processos da $\omega$-oxidação e $\beta$-oxidação;

Scott e Jones (2000) afirmaram que a velocidade de degradação tende a ser mais rápida para homólogas de LAS de maiores cadeias carbônicas alquílicas e dentre estes, isômeros com grupo sulfenil mais próximos do centro da cadeia carbônica apresentaram degradação biológica mais lenta em relação aos demais. O favorecimento de relações sintróficas entre os microrganismos com a participação de alguns para a degradação da cadeia alquílica e outros na mineralização do anel aromático também foram citadas pelos autores.

A degradação anaeróbica de LAS iniciou a ser estudada recentemente, a partir da primeira década do século XXI. Estes estudos recentes têm demonstrado que a degradação do LAS é possível. As pesquisas tem sido realizadas com a utilização de reatores UASB (reator anaeróbico de fluxo ascendente de mato de lodo) (ALMENDARIZ et al. 2001; MONGENSEN et al. 2003; SANZ et al., 2003; LOBNER et al. 2005), reator contínuo de mistura completa (CSTR) (MONGENSEN et al. 2003), reator anaeróbico horizontal de leito fixo (RAHLF) (OLIVEIRA et al. 2009; DUARTE et al. 2008), reator de leito fluidificado (RALF) (OLIVEIRA et al. 2010), reator operado em bateladas seqüenciais (DUARTE et al. 2010).

Apesar das rotas metabólicas da degradação anaeróbica do LAS não ser totalmente elucidada pode-se tecer as seguintes considerações:

- LAS pode ser utilizado como fonte de enxofre por bactérias anaeróbicas em condições limitadas de sulfato (DENGER e COOK,1999).

- Ácido benzenosulfônico e benzoaldeído podem ser produzidos como metabolitos na degradação anaeróbica de LAS (MONGENSEN et al., 2003).

- Benzeno e tolueno foram encontrados em efluentes de reator anaeróbico usado na degradação de LAS (DUARTE, et al. 2006). 


\section{CONCLUSÃO}

Através deste trabalho foi possível se observar as características do surfactante mais comercializado em todo o globo, Alquil benzeno sulfonado linear (LAS), assim como os principais impactos ambientais associados à liberação desta substância nos ambientes terrestres e aquáticos.

Os problemas associados ao LAS se relacionam com a desnaturação de proteínas, destruição de membranas radicalares, deficiências na reprodução de invertebrados e nos ambientes aquáticos associados a deficiências nas taxas de oxigenação natural e na tensão superficial da água; problemas na locomoção e na reprodução de microrganismos, crustáceos e peixes, entre outros. Somente em concentrações mínimas, abaixo de 0,29 mg/L de LAS que foi possível se perceber a redução de forma significativa os efeitos nocivo deste surfactante aniônico.

Desta maneira os usos de tecnologias capazes de realizar a degradação e a remoção do poluente LAS são de valor estratégico relevante neste início de século XXI. As maiores eficiências de remoção se dão através dos processos biológicos de tratamento com eficiência de até $80 \%$ e que ainda podem ser potencializadas com o uso combinado com processos físico químico. Esta eficiência na remoção possibilita além da preservação da macro e micro fauna, menores restrições ao reuso de águas e do lodo das estações de tratamento de esgoto, contribuindo para ações de reinserção destes compostos nos processos produtivos, vital para o alcance do desenvolvimento sustentável dos ambientes urbanos.

\section{REFERÊNCIAS BIBLIOGRÁFICAS}

1. ALMENDARIZ, F.J; MERAZ,M.; SOBERON,G.; MONROY,O. Degradation of lineal alkybenzenesulphonate (las) in an acidogenic reactor bioaugmenteg whit a pseudomonas aeruginosa (m113) strain. Water Science and technology, v. 44, n.4, p 183-188, 2001.

2. ANDER, P., MARZULLO, L.Sugaroxidoreductase and veratryl alcohol oxidase as related to lingnindedradation.J.Biotechnol.53: 115 - 131, 1997.

3. BRAGA, B.; HESPANHOL, B.; CONEJO, J. G. L.; BARROS, M. T. L; SPENCER, M.; PORTTO, M.; NUCCI, N.; JULIANO, N.; EIGER, S. Introdução à Engenharia Ambiental. São Paulo: Prentice Hall, 2002.

4. BITTON, G. Wasterwatermicrobiology. New York, 17-19p, 1994.

5. BORJA, R., MARTIN, A., ALONSO, V., GARCIA, I., BANKS, C. G.Influence of diferente aerobic pretreatments on the kinetics of anaerobic digestion of olive mil wastewater. Water Research. 29: 2: 489-495, 1995.

6. DENGER, K.; COOK, A.M. Assimilation of sulfur from alkyl-and arysulfonates by clostridium spp. Archives of Microbiology, v.167, n 2-3, p.177-181, 1997.

7. Di Corcia A. Characterisation of surfactants and their biointermediates by liquid chromatography-mass spectrometry. J Chromatogr, A 1998; 794:165- 85.

8. DUARTE.I.C.S.; OlIVEIRA. L. L.; BUZZINI, A. P.; ADORNO, M. A. P.; VARESCHE, M. B. A.Development of a method by hplc to determine las and its application in anaerobicreators. Journal of the Brazilian chemical society, v.17,p. 7, Nov-Dec, p. 1360-1367, 2006.

9. DUARTE. I. C. S.; OLIVEIRA. L. L.; SAAVEDRA, N. K. D.; FANTINATT-GARBOGGINI, F.; OLIVEIRA, 
V. M.; VARESCHE, M. B. A. Evaluation of the microbial diversity in a horizontal-flow anaerobic immobilized biomass reactor treating lineal alkybenzenesulphonate. Biodegradation, v. 19, n. 3, Jun, p. 375-385, 2008.

10. GARCIA, M. T.; CAMPOS, E.; RIBOSA, I.; LATORRE, A.; SANCHEZ-LEAL, J. Anaerobic digestion of lineal alkybenzenesulphonates : Biodegradation kinetics and metabolite analysis. Chemosphere, v. 60, n.11, sep, p. 1636-1643, 2005.

11. GHARASALLAH, N., LABAT, M., ALOUI, F., SAYADI, S.The effect of Pahanerochaetechrysosporium pretreatment of olive mill waster waters on anaerobic digestion. Resources, Convertion and Recycling 27: 187 - 192, 1999.

12. KOTSOU, M., KYRIACOU, A., LASARIDI, K., PILIDIS, G. Integrated aerobic biological tratment and chemical oxidation with Fento's reagent for processing of green table olive wastewater. Process Biochemistry. 39: 1653 -1660, 2004.

13. LOBNER, T.; TORANG, L.; BATSTONE, D. J.; SCHMIDT, J.E.; ANGELIDAKI, I. Effect of process stability on anaerobic biodegradation of las in uasb reactors. Biotechnology and Bioengineering, v. 89, n. 7, Mar, p. 759-765, 2005.

14. MATTHIJS, E., DE HENAU, H. Detetmination of linearalkybenzenesulphonates in aqueous samples, sediments, sludges and soil using HPLC. Tenside Surfactants Detergents, v. 24, p. 193198, 1987.

15. MONGENSEN, A. S.; HAANGENSEN, F.; AHRING, B. K. Anaerobic degradation lineal alkybenzenesulphonate.Environmental toxicology and Chemistry, v. 22, n. 4, p. 706-7011, 2003.

16. MUNGRAY, A. K., KUMAR, P. Degradation of ainionicsurfactans during drying of UABSR sludges on sand drying beds.Journal of Environmental Management, v. 88, p.995-1002, 2008.

17. OLIVEIRA,L .L. , DUARTE,I. C. S., SAKAMOTO, I. K., VARESCHE, M. B. A. Influence of support material on the immobilization of biomass for the degradation oflinealalkybenzenesulphonate in anaerobic reactors. Journal of Environmental Management, v. 90,n. 2, p.1261-1268, 2009.

18. OLIVEIRA, L. L.; COSTA, R. B.; OKADA, D. Y.; VICH, D. V.; DUARTE,I. C. S.; SILVA, E. L.; VARESCHE, M. B. A. Anaerobic degradation of lineal alkybenzenesulphonate (las) in fluidized bed reactor by microbial consortian in different support materials. Bioresoursethechnology, v. 101,n. 14, p. 5112-5122, 2010.

19. PAINTER, H. A.; ZABEL, T.The behavior of lasinsewagetreatment.Tensidesurfactants Detergents, v. 26, p. 108- 115, 1989.

20. PAPAGIANNI, M. Fungal morphology and metabolito production in submerged mycelia process.BiotechnologyAdvances, 22: 229 - 235, 2004.

21. SANZ, J. L.;CULUBRET, E.; DE FERRER, J.; MORENO, A.; BERNA, J. L. Anaerobic biodegradation of lineal alkybenzenesulphonate (las) in upflow anaerobic sludge blanket (uasb) reactors.Biodegradation, v.14, n.1,p. 57-64, 2003.

22. SCOTT, M. J.; JONES. M. N. the biodegradation of surfactants in the environment. Biochimica Et BiophysicaActa-Biomembranes, v.1508,n. 1-2. Nov,p.235-251, 2000.

23. SCHÖBERL, P. Basic principles of LAS biodegradation.Tenside Surfactants Detergents, v. 26, p. 86-94, 1989. 
24. TELLES.D.A; COSTA.R.H.P.G. (Cord).Reúso da água conceitos, teorias e práticas, São Paulo: Editora Blucher, $1^{\circ}$ edição, 2007.

25. VENHUIS, S. H.; MEHRVAR, M. Health effects,evironmental impacts, and photochenical degradation of selected surfactants in water. International Journal of photoenergy, v. 6,n. 3,p. 115-125, 2004.

26. VERGE, C.; MORENO, A.; BRAVO,J.; BERNA, J.L. Influence of water hardness on the bioavailability and toxicity of linear alkylbenzenesulphonate (las). Chemosphere, v.44,n.8, p. 1749-1757, 2001.

27. Ying, G. -G. Fate, behavior and effects of surfactants and their degradation products in the environment. Environment International v, 32p. 417- 431, 2006. 